\title{
Future time orientation and its relevance for development as action
}

\section{Gisela Trommsdorff}




\title{
VII. Future Time Orientation and Its Relevance for Development as Action
}

\author{
G. TROMMSDORFF*
}

\section{Introduction}

Slogans such as "no future" have frequently been used recently to describe the unattractive situation of adolescents who are faced with enormous economic. social, and political problems and insecurities. It should be interesting to study how adolescents themselves anticipate and evaluate their future and which variations may exist among certain groups of adolescents. This should be especially interesting when pursuing the more general question of which function future orientation may have for the development of adolescents. One may assume that the way adolescents anticipate and evaluate their future influences their life planning, decision making, and behavior. One may even hypothesize that adolescents construct their own future according to the future orientation they develop.

\section{Development of Future Orientation}

Let us assume that a main developmental task of adolescents is to establish a concept of self identity. This includes subjective theories about one's present but also about one's future self - including wishes, hopes, expectations, and plans for the attainment of one's goals in the future. In the pluralistic value system of our society, adolescents are offered conflicting goals to strive for; clear value priorities are not explicated, and adolescents have to find out themselves which way of life is best for them. Such variety of goals and life styles may create insecurity, especially when criteria for decision making are missing.

Adolescents have to face this insecurity not only with respect to the formation of their present and future self identity but also with respect to their future environment: They cannot develop clear expectations about where they will be living. with whom they will interact, what kind of tasks and responsibilities they will have to fulfill. How will they develop a future orientation? What qualities does their future orientation have? Having this general question in mind. I will first explain the concept of future orientation, then I will briefly discuss some studies on the development and on the be-

* Universität Konstanz; Postfach 5560;

D- 7750 Konstanz 
havioral relevance of future orientation which are of some interest for research on substance use in adolescence.

\section{Conceptualization of Future Orientation}

In our own studies. we departed from Lewin`s (1948: 1965) notion that future orientation is one aspect of time perspective, encompassing goals, aspirations, fears, and hopes for the near and distant future. Following the tradition of expectation-x-value-theories (Atkinson, 1964: Vroom, 1964; Heckhausen. 1980; Gjesme, 1981) we have conceptualized future orientation as a complex cognitive-motivational phenomenon: the anticipation and evaluation of the future self in interaction with the environment (Trommsdorff, 1983).

In its motivational and affective quality, future orientation is related to the satisfaction of subjective needs: it includes approach and avoidance tendencies and can be described as more optimistic or pessimistic, or as more positive or negative. The motivational and affective aspects of future orientation are interrelated with the person's value and goal system and with cognitive schemata about the self and the environment. These are activated according to the situational context and the thematic content of the relevant anticipations. The cognitive aspects of future orientation can be described according to the structure of anticipations. These can be more or less extended, differentiated. precise, coherent. and/or realistic. Furthermore, the future may seem to be more or less controllable, and one's future orientation may rather focus on external or internal causes of future events.

Before future orientation is transformed into life planning, decision making. and behavior, further variables come into play: the relevance of goals embedded into one's future orientation, judgments of self competence and environmental conditions in the present and in the future, heuristic competence in problem solving, readiness to tolerate frustrations, to delay immediate fulfillment of one's needs, and flexibility in restructuring one's goals in case of nonattainability. Since these factors are not necessarily stable person variables. the situational context, which may activate one or the other factor. has also to be taken into consideration. Since systematic studies on the development of future orientation (taking into account the interrelations with these further cognitive and motivational variables) have not yet been carried out. we have to restrict ourselves to studies which may clarify some developmental conditions of future orientation. Here, I will focus on four factors relevant for this question: 1. impact of situational demands; 2. processes of cognitive maturation: 3 . impact of social learning in family, school or work: and 4. interaction processes.

\section{Impact of Situational Demands}

The structure of one's future orientation depends, first of all, on the cognitive representation of present and future situations. If fewer instrumental ac- 
livities are necessary to achieve one's goals. one's future orientation will be structured less complexly. Or. if goals in the distant future seem difficult to attain. it may be more reasonable to structure one's future orientation in terms of available rewards in the near future. This should be the case for rather deprived groups of adolescents.

As we know from studies on economically disadvantaged groups, their future orientation is indeed more directed to events in the near future, as compared to the more extended future orientation of more privileged adolescents (see LeShan. 1952. and Brock \& Del Giudice, 1963, for a comparison of lower and middle class children: Shannon, 1976, for children from minority as compared to majority groups). In the same line, adolescents from a lower as compared to a higher social class structure their future less complexly in most domains of life (Lamm. Schmidt, \& Trommsdorff, 1976). A rather short or more extended future orientation (and related preferences for delay of gratification) thus can be interpreted as a realistic appraisal of, and coping with. the given social setting.

The situation-specific character of future orientation may be dramatically demonstrated by the impact of situational variables in real life situations such as institutionalization. In our studies on imprisoned juvenile delinquents and army draftees at different times of their institutionalization, as compared with noninstitutionalized delinquent and nondelinquent adolescents, we were able to observe enormous differences between these groups (Trommsdorff \& Lamm, 1980). The future orientation of institutionalized adolescents (delinquents and draftees) was dominated by the event of their discharge. and changed with approaching time of release, increasingly including events related to the time of discharge. Their future orientation was filled with anticipations of problems anci events after release.

The situation-specific structure of the person's future orientation thus may function as a problem-oriented approach to realistically prepare for certain events in the future. But future orientation is not only a situation-specific phenomenon. It develops in relation to other person variables in early childhood. partly determined by processes of cognitive development and partly influenced by external social learning conditions. which produce a future orientation with more or less stable characteristics. The stability of a person's future orientation can be seen from our results on the striking similarities between adolescents and adults sharing the same social (educational and occupational) background (Trommsdorff. 1983).

\section{Cognitive Maturation}

Following Piaget (1946. 1966). the development of time concepts is part of the child's general ccenitive development. Formal operational intelligence enables the child to anticipate future events and to think in terms of future consequences. Along this line. empirical data show that children and adolexcents learn to structure their future more complexly with increasing age and related cognitive maturation. They increase the extension of their time 
perspective into the future (Klineberg. 1967: Shannon. 1975): they become more realistic (Klineberg. 1967: Trommsdorff, Burger, Füchsle. \& Lamm. 1978 a). and they learn to take into account specific causes of future events.

\section{Impact of Social Learning}

Besides endogenous processes of cognitive maturation which are an important precondition for the development of future orientation. learning experiences in family. school or work influence the development of future orientation in its cognitive, affective, and motivational aspects. Several studies on adolescents from different social class, different ethnic and cultural background. and different educational level. clearly demonstrate significant effects of the social environment on the development of future orientation (for a summary, see Trommsdorff, 1983).

Motivational and Cognitive Factors Related to Social Roles. Adolescents' education influences their level of aspiration, goal setting, and anticipation of instrumental activities necessary for achieving these goals. The more relevant goals are then structured in a more differentiated way. However, adolescents from higher educational background need not necessarily structure their future more complexly. Cognitive training, but also motivational stimulation is important for the development of their future orientation. In several of our studies we were able to show that differences in future orientation of adolescents from different educational levels are not only related to differences in cognitive ability and intelligence. For example, adolescents from lower as compared to higher educational level structured their future more differentiatedly in certain areas, such as occupation (Trommsdorff, Lamm, \& Schmidt, 1978 b). Likewise, Bouffard (1981) has shown for African adolescents that schooling alone is no necessary condition for an extended future orientation.

As an example for the impact of social roles let us have a closer look at the longitudinal study on adolescents from different educational levels (Trommsdorff et al.. 1978b). All adolescents went to school at the time of the first measurement: nine months later. one group, the former grammar school pupils. had already started to work. while the other group of high school pupils still went to school. During the period of time from the first to the second measurement. the lower educated adolescents (grammar school) had considerably changed in their future orientation. They now structured the occupational domain of their future much more precisely than before and more precisely than the more educated students. Furthermore, they increased their belief in internal control of the future: At the first point of measurement. their belief in internal control of the future had been lower than that of high school students. These results support our assumption that motivational factors related to social roles can influence the structure of one's future orientation. 
Another example for the impact of social roles on future orientation may be taken from our studies comparing the future orientation of female and male adolescents. A general finding in all of these studies was that significant differences occurred with respect to the thematic content of females' and males future orientation (Trommsdorff \& Lamm. 1975: Lamm et al., 1976: Trommsdorff et al.. 1978 a. b: Trommsdorff. Burger. \& Füchsle, 1980). In accordance with the traditional sex role. females, especially those from lower social levels. were more likely than males to focus their hopes and fears on the family domain. Their future orientation clearly was also directed towards the attainment of occupational goals. but was extended only to goals in the rather near future (Lamm et al.. 1976). Independent of educational and social level. females generally anticipated more problems in the family and occupational domain than males (Trommsdorff et al., 1980). Furthermore. in most studies we found a more profound belief in external control of the future for females than for males (for a summary see Trommsdorff. Burger. \& Füchsle. 1982: Trommsdorff, 1983).

These results support the hypothesis that females as compared to males have to deal more with conflicting role expectations, and have experienced less success. which is necessary to believe in one's own competence and positive environmental responsiveness. The general finding of these and other studies is that sex roles and related social and cognitive-motivational learning clearly influence adolescents' future orientation.

Impact of Child-Rearing Practices. In order to study the functions of specific learning conditions for the development of future orientation in more detail, we may refer to studies on child-rearing practices and their effects on the development of self concept. belief in one's own abilities, trust in one's environment. self control, and delay abilities (Rotter, 1966; Mischel, 1974; Stapf. Herrmann. Stapf, \& Stäcker, 1972). In line with the theorizing in these studies. we assumed that the experience of parental acceptance would foster a positive. self-assured future orientation in the child. As a matter of fact, we liere able to show for adolescents from different age groups that persons who perceived their parents as loving and supporting had a more trusting, hopeful. and positive future orientation. believed more in personal control of their future. and were more willing to delay gratifications (Trommsdorff et al.. 1978 a).

To summarize: In several studies, the impact of cognitive development, formal cognitive learning. but also of social settings, roles, and related learning experiences on the development of a rather stable future orientation has been demonstrated. For the moment. these relationships can only be formulated in a very rough and global way. and many questions remain unanswered.

Especially the stibtle influences of social expectations, for example the expectations of parents. teachers. friends. but also of mass media and public 
opinion. on the development of the adolescents' future orientation are so far hardly known.

\section{Interaction Processes}

Recent studies on the Pygmalion effect in the classroom (Rosenthal \& Jacobson, 1968; LeVine \& Wang, 1983) point out the impact of teachers' expectations on the self-concept and expectations of students. Results from our own studies on the relationship between teachers' expectations and the future orientation of pupils very clearly indicate strong interdependencies between both: Adolescents who are expected to be successful later in their life, hold a more optimistic future orientation and believe more in internal control of their future (Trommsdorff, 1983). Here, the question arises to what extent preexisting cognitive-motivational schemata determine which information is selected and how it is integrated into one's future orientation; and on the other hand, how one's future orientation determines one's decision making and behavior - which, in turn, may influence the way other people evaluate one's self, anticipate one's future, and then direct their interpersonal behavior accordingly.

These questions on the presumably complicated processes of interactions between one's future orientation and behavior, and the expectations and behavior of one's social environment, are especially interesting when studying the development of future orientation in adolescents.

As far as the first part of this interaction is concerned, we have to assume that the relationship between future orientation and behavior is mediated by other person variables such as self-concept, anxiety, problem solving abilities, etc., and by given situational variables which may activate certain hopes or fears. We have enough reason to expect complicated interrelations between these variables. which are not unidirectional in their effect. However, our present data do not yet allow for testing the sequence of such interactions.

In the following. I will give some examples to demonstrate the close relationship between future orientation. individual behavior, and social environment. Let me refer to a selected group of adolescents - juvenile delinquents.

\section{Future Orientation and Behavior}

A less extended and less complex future-time perspective of delinquents as compared to nondelinquents has often been interpreted as a precondition for delinquency. and an indicator of delinquents' inability to control their impulses and to delay gratifications (e.g.. Barndt \& Johnson. 1955; Stein, Sarbin \& Kulik. 1968: Black \& Gregsun. 1973). However, the relationship between delinquency. delay of gratification. and extension of future time perspective is not so clear. These relationships were tested for male (Tromms- 
dorff \& Lamm. 1980) and for female delinquents (Trommsdorff. Haag, \& List. 1979).

In the following. I will present our study on (drug-using and nonusing) female delinquents.

Method. In this study, our sample was composed of 55 female delinquents ( 15 were on probation. 30 were nonusing delinquents in prison, and 10 were imprisoned because of diverse drug problems); 30 female workers served as a control group. Due to the small sample size, the data should be interpreted with caution.

The subjects were rather homogeneous with respect to age (18 to 24 years) and socio-economic background. All subjects completed a questionnaire containing possible future life events that had been noted by other delinquents in a pilot study as relevant hopes and fears (e.g., to feel accepted by neighbours: to have friends; to have solved financial problems). For each item. subjects were asked to indicate the probability (expectation) and the desirability (evaluation) of the event's occurence, and the time when the event would occur (extension).

Results. Contrary to the often assumed difference in extension of future time perspective between delinquents and nondelinquents, no such differences occurred for positive events (hopes).

However, with respect to fears. female delinquents (drug-using and nonusing) had a significantly less extended future orientation as compared to nondelinquents. Furthermore, they judged the occurrence of feared events as being more probable.

This result is in contrast to the often assumed wishful thinking of delinquents (Landau, 1975: 1976). To summarize, our data demonstrate that delinquents have a rather pessimistic view of their future. That was also true for male delinquents (Trommsdorff \& Lamm, 1980). Let us now have a look at drug using vs. nonusing female delinquents.

\section{Delinquent Drug Users v'. Nondelinquent Females}

Our results demonstrated an overall tendency of institutionalized delinquents (drug users and nonusers) to be more pessimistic than nondelinquents. This was shown for both components of future orientation, extension and probability estimations.

Substance users had a less extended future orientation for negative future events (fears): they also indicated higher probability estimations for the occurrence of feared events than nondelinquents $(t=2.52, d f=28, p<.02$; $t=-2.74 . d f=12.9, p<.02)($ see Table 1$)$.

As for specific domains of life, delinquent users as compared to nondelinquents believed more strongly in the probability of occurrence of their fears in the economic and personal spheres. 
Table 1. Future orientation of drug-using adolescents

\begin{tabular}{|c|c|c|c|}
\hline & $\begin{array}{l}\text { A } \\
\text { Non-drug-using } \\
\text { delinquents }\end{array}$ & $\begin{array}{l}\text { B } \\
\text { Non-drug-using } \\
\text { nondelinquents }\end{array}$ & $\begin{array}{l}\mathrm{C} \\
\text { Drug-using } \\
\text { delinquents }\end{array}$ \\
\hline \multicolumn{4}{|l|}{ Extension $^{1}$} \\
\hline \multicolumn{4}{|l|}{ Hopes } \\
\hline Economic & 9.51 & 8.41 & 5.77 \\
\hline Social & 2.57 & 4.18 & 4.63 \\
\hline Self & 4.82 & 4.85 & 3.86 \\
\hline Total & 5.63 & 5.81 & 4.76 \\
\hline \multicolumn{4}{|l|}{ Fears } \\
\hline Economic & 5.57 & 9.85 & 3.80 \\
\hline Social & 17.40 & 19.24 & 10.43 \\
\hline Self & 8.98 & 16.52 & 6.23 \\
\hline Total & 10.59 & 15.20 & 6.82 \\
\hline \multicolumn{4}{|c|}{ Probability Estimation ${ }^{2}$} \\
\hline \multicolumn{4}{|l|}{ Hopes } \\
\hline Economic & 5.81 & 7.15 & 6.18 \\
\hline Social & 7.83 & 8.00 & 7.13 \\
\hline Self & 7.27 & 7.82 & 7.76 \\
\hline Total & 6.97 & 7.66 & 7.02 \\
\hline \multicolumn{4}{|l|}{ Fears } \\
\hline Economic & 5.09 & 3.28 & 5.70 \\
\hline Social & 4.12 & 4.34 & 5.77 \\
\hline Self & 4.52 & 3.23 & 5.07 \\
\hline Total & 4.57 & 3.62 & 5.51 \\
\hline
\end{tabular}

$p<0.05$ for $\mathrm{A}$ vs. $\mathrm{C}: p<0.05$ for $\mathrm{B}$ vs. $\mathrm{C}$

1 Number of years from now

$20=$ not at all probable $\ldots 10=$ very certain

Furthermore. delinquent drug users were more pessimistic than nondelinquents with respect to the belief that their self-centered fears will soon come true $\left(t=2.36, d f^{\prime}=34 . p<.03\right)($ see Table 1$)$.

\section{Delinquents: Drug Users vs. Nonusers}

Extension. Looking at differences between drug-using and nonusing delinquents in more detail. we found that for only one domain of life, drug users were more optimistic than nonusers: They believed their hopes for economic well-being would be fulfilled in the near future $(t=2.34, d f=24, p<.03)$. However, especially with respect to social acceptance and integration, drugusing delinquents were more pessimistic than nonusing delinquents $(t=2.19 . d f=53 . p<.03)$. 
Probability Estimation. Delinquent drug users believed more strongly than delinquent nonusers in the fulfillment of their fears concerning social integration $(t=2.41$. $d f=54 . p<.02)$ (see Table 1$)$.

To summarize. these results show that the future orientation of drug-using delinquents was generally more pessimistic than that of nonusers. This is indicated by their relatively less extended future orientation and high probability judgments with respect to fears.

Discussion. Studying the future orientation of drug-using and nonusing adolescents. One may hypothesize that the respective future orientation of these groups mirrors their past but also their probable future experiences. Experience of failure and lack of social acceptance may have affected the generalized attitude that self-ideal and social reality are too far apart, and self-fulfillment cannot be expected in the future. This generalized pessimism - the feeling of hopelessness and worthlessness - may have contributed to the decision to take drugs. On one hand, such a decision may help to deal with one's fears: on the other hand. however, fears concerning the distant future increase. Furthermore. such a decision for socially disapproved behavior supports negative responses from the social environment.

Here. we may observe a vicious circle between future orientation (as cognitive-motivational predisposition for such decision) and environmental conditions: the latter are influenced by these individual decisions in such a way that they reinforce the negative anticipations and fears of the adolescents and consequently contribute to their alienation. Thus, an imbalanced. pessimistic future orientation gains self-fulfilling qualities.

\section{Development of Future Orientation and Behavioral Correlates: A Representative Study}

So far we have discussed some conditions for the development of future orientation and pointea out the relation between future orientation and behavior. and the interrelations between both and the social environment.

The studies I have reported above had been designed to analyze some aspects of future orientation. and to test some specific conditions for its development and behavioral relevance. However. the scope of all of these studies is rather limited: they are all based on relatively small samples and focus onIs on some selected variables. Therefore, we have to question the generalizability of our results and the ecological validity of the data.

In search for more information about the empirical foundation of our hypotheses and post-hoc interpretations on the development and behavioral relevance of future orientation, we may turn to look at a recently published representative study on attitudes, life styles, and future orientation of German adolescents - the Shell study (Jugendwerk der Deutschen Shell, 1982).

Though this study must be criticized because of its methodological shortcomings (Hübner-Funk. Lösch. Rathgeber. \& Schefold, 1982/83), and 
though future orientation has been conceptualized differently here, we may nevertheless refer to this study and some specific data which are of interest for our question. Here, we have the chance to get data on future orientation gathered in a broader context and in connection with other data on the social background and behavioral intentions of adolescents.

The general finding of the Shell study is that $58 \%$ of German adolescents are predominantly pessimistic about their future. Now, let us have a closer look at the concept of future orientation used. and at some correlated data.

\section{The Shell Study: Some Results}

In the Shell study (1982), several scales measuring future time perspective are used, all of them focussing on environmental, not on private aspects, of the future.

Belief in Control of the Future. One of these scales is especially interesting. It measures a person's belief in his/her personal control of social environmental change (p. $346 \mathrm{ff}$ ). The results show that adolescents low as compared to high in this belief:

1. differ with respect to other aspects of their future orientation: they tend to

- have less extended expectations about their future;

- be less interested in becoming adult soon:

- be more pessimistic about political, social, environmental, and economic aspects of their future:

2. differ with respect to their social background and roles: they tend to

- belong to lower social status groups and are females;

3. differ with respect to their behavioral preferences, tending to:

- be less active in sports clubs;

- feel closer to punkers:

- support "alternative" groups and green political parties more frequently.

Optimism/Pessimism. Another question (unfortunately consisting of one item only) focusses on general optimism/pessimism.

With respect to their social roles, the following differences are noted: The more pessimistic groups tend to:

- consist of girls. older pupils. and students:

- stem from the middle class:

- have experienced little parental acceptance but much conflict with parents.

Another scale measuring optimism/pessimism includes 12 items describing possible future economic. social, and environmental developments.

The results are quite similar to the findings cited above: More pessimistic adolescents have tried earlier in their development to become in- 
dependent. however, they now prefer to postpone adult responsibilities and "independence": they feel closer to peers than to parents, and they support protest movements.

Concerning other aspects of their future orientation, they have fewer goals and hopes for the future, and they believe themselves to be less in personal control of their future.

\section{Conclusion}

When summarizing the results from the empirical studies reported so far, we may come to the following hypotheses on the development and behavioral relevance of future orientation:

1. The more social settings require the testing of one's competence and allow for the awareness of one's abilities and options, the more subjective relevance is attached to this domain, and the more differentiated one's future orientation is structured with respect to this domain.

We have observed this relationship in the development of future orientation: Working adolescents structured the occupational domain more precisely as compared to nonworking adolescents. We have also observed a more differentiated structure of the family domain in girls' as compared to boys' future orientation.

To state this hypothesis in a more generalized way: The structure of specific areas of one's future orientation depends on the development of social motives and related goals.

2. The more social settings require and reinforce personal responsibility and independence, the more one's future orientation focuses on the belief in personal control.

According to the Shell study, lower-class adolescents are less convinced of personal control of environmental and social changes, possibly because of perceived difficulties in gaining influential positions later in their life. However. what the question of controlability of one's personal future is concerned, adolescents with lower status may well develop such belief if they are given the chance to take some responsibility for their actions, as we have seen in our study on working adolescents (Trommsdorff et al., 1978 b).

The data from the Shell study and our own studies are in accordance with respect to the sex-specific difference in this aspect of future orientation: Females believe less than males in personal control of their private and public future. Possibly, female adolescents experience less opportunities for testing their abilities and taking responsibility for activities that they would like to engage in. They trust less in their own abilities, as has been shown in other studies (Feldman-Summers \& Kiesler, 1974).

3. Here we hit a related aspect of future orientation: the positive or negative evaluation of the future. The less social settings allow for the experience of success and social acceptance, the more pessimistic one's future orientation is colored. 
According to the data from the Shell study. girls are more pessimistic than boys. This is in line with our findings that girls experience more internal conflicts when structuring their future: they anticipate more difficulties and uncertainties in attaining their goals (Trommsdorff et al.. 1980). Other studies on life satisfaction and well-being of female as compared to male adolescents support this notion that girls have greater difficulties in defining their self-identity (Burke \& Weir. 1978).

Referring again to our hypothesis. we should also expect a rather negative and pessimistic future orientation for those adolescents whose social environment has not offered enough opportunities to test their abilities, to experience success and acceptance even in case of failure.

As a matter of fact. data from the Shell study and our own studies are in line with this hypothesis. According to Trommsdorff et al. (1978a), those adolescents who have experienced little parental acceptance and who report conflicting interactions with their parents, have a more pessimistic future orientation than those adolescents who feel accepted. The pessimistic group in the Shell study rather prefers interactions with peers than with their parents: here they may receive social support and warmth which they are missing in their family.

How can we explain the more pessimistic future orientation of middleas compared to lower-class adolescents? The less educated adolescents had to enter the adult role much earlier, they had to take over adult responsibilities and had experienced controlability of their situation. In contrast, the more highly educated middle class adolescents are living in a rather artificial world: real life has only been mediated by symbolic cognitive processes in school or mass media, but rarely by the experience of real consequences of decision making and behavior. As long as adolescents are not required to take personal responsibility for their behavior, they may not learn to structure means-ends relationships to cope with frustrating situations. restructure goals and make realistic judgments about their own competence. the responsiveness of the environment, and the interaction between both in the future. They will fail in one crucial developmental task: to develop a positive self-concept. a related positive future orientation, and realistic life planning.

4. Let us finally discuss the hypothesis dealing with the relationship between future orientation and behavior. The more future orientation is pessimistic and structured in terms of low personal control and negative action outcomes. the less adolescents are likely to accept and conform to common social norms: the more they tend to choose "alternative" life styles even if these are linked to negative sanctions. The data from the Shell study (e.g., preference for punkers: alternative groups: protest movements) and our own data on male and female delinquents are generally in line with this hypothesis.

When anticipating primarily negative outcomes, it seems less worthwhile to undertake investments. to control oneself, to tolerate frustrations, or to 
pursue far-reaching goals. Since it does not matter anyhow what one does, one might as well look for self-fulfillment in the very near future and choose activities which are socially disapproved and which have negative consequences for one's distant future.

Conflicts with parents and negative sanctions from the adult world will only reinforce the adolescents' existing cognitive schemata about the self and the environment and strengthen the tendency to reject or postpone adult roles and responsibilities. Thereby, one will further avoid realistically testing one's abilities and options and reinforce environmental responses of rejection.

Thus. in the process of adolescent development, an imbalanced pessimistic future orientation may stabilize and gain self-fulfilling qualities.

\section{Outlook}

Further systematic studies on the development and behavioral consequences of future orientation should clarify the function of future orientation for the development of adolescents. According to our present knowledge on the behavioral aspects of future orientation, one may assume that future orientation functions as a means to cope with developmental tasks by structuring and evaluating one's future. Especially in modern industrialized societies where changes in the social and economic system progress rapidly and affect a person's course of life, it seems necessary to develop a realistic, differentiated. well-structured, extended, and positive future orientation which allows for anticipating future developments and alternatives in order to prepare for taking over new roles, adapting to new situations, and solving new problems.

However, in our society, lack of responsibility and participation in the adult world will make it extremely difficult for adolescents to develop a well-balanced and realistic future orientation. Social learning is mostly mediated by symbolic and cognitive processes in school and by mass media, but rarely by concrete experiences and real consequences of decision making in other areas of life. This makes it difficult to learn the structuring of meansends relations, to cope with given situations, solve problems, endure frustrations, restructure one's goals, and to make judgments about one's own competence, environment, and future. When adolescents finally enter the adult world without having had a chance to adequately prepare for taking these roles and responsibilities. disappointment and frustrations may result - an effect which is frequently reported for students after their first year of work (Burger \& Seidenspinner, 1979).

Further factors may contribute to these difficulties. One is related to the pluralistic value system of our society. Adolescents are offered many alternative goals to strive for: clear value priorities are not available, and they have to find out for themselves which way of life is best for them. It may well be 
that such variety of goals and life styles creates insecurity for adolescents in search of self-identity and criteria for self-evaluation.

Furthermore, it is difficult for adolescents in our society to face the actual uncertainty of whether they will ever be able to achieve a social status and a standard of living which is comparable to that of their parents. In times of social change when the previously observed social and economic progress has come to an end and stagnation or retrocession takes on, the insecurities which adolescents have to face are increasing. Under these circumstances, who is surprised if a pessimistic future orientation and related experience of alienation stabilizes?

It is probably most difficult for adolescents in our society to find the right balance between extreme pessimism and unrealistic optimism as long as they are given only limited opportunities to empirically test their competence and the actual possibilities of their environment. However, this is only one side of the coin: it is not only the society which deprives our adolescents of participation in the adult world. Such deprivation also results from their future orientation. A pessimistic future orientation can block the motivation for any such activities and thus serves as reinforcing factor in a vicious circle of constructing one's future according to one's future orientation.

One may even ask whether a certain degree of unrealistic optimism and "illusion of control" is necessary to start acting on one's environment according to one's goals. Such optimism may allow one to face the manyfold problems lying ahead, it may serve as an excuse in case of failures, it may allow one to tolerate frustrations which come up in the process of dealing with these problems and it may encourage to continue even in case of failure. For example, the study of Wilpert (1980) on Turkish adolescents in the FRG (West Germany) shows that this deprived minority group is characterized by an enormous level of aspiration and extreme optimism in pursuing seemingly unrealistic goals.

Here. we have to ask whether the development of such illusions and unrealistic optimism depends on more than our before mentioned conditions. It may be difficult to find these specific economic, ecological, and cultural conditions in our own society. Therefore, one may think of broadening our knowledge about the function of future orientation for development-as-action by cross-cultural studies, possibly including such cultures where adolescent development is embedded in a specifically future-oriented value system.

\section{References}

Atkinson, J. W. (1964) An introduction to motivation. Princeton. N. J.: Van Nostrand Barndt. R. J. \& Johnson. D. M. (1955) Time orientation in delinquents. Journal of $A b$ normal and Social Psychology, 51, 343-345 
Black. W. A. M. \& Gregson. R. A. M. (1973) Time perspective, purpose in life, extraversion and neuroticism in New Zealand prisoners. British Journal of Social and Clinical Psichologl: 12.50-60

Bouffard. L. (1981) La perspective future chez les Africaines. Unpublished manuscript, Collège de Sherbrooke. Québec

Brock. T. \& Del Giudice, C. (1963) Stealing and temporal orientation. Journal of Abnormal and Social Psichology, I, $91-94$

Burger. A. \& Seidenspinner. G. (1979) Berufliche Ausbildung als Sozialisationsprozeß. Munich: Juventa

Burke. R. \& Weir, T. (1978) Sex differences in adolescent life stress, social support, and well-being. Journal of Psychology, 98, 277-288

Feldman-Summers. S. \& Kiesler, S. B. (1974) Those who are number two try harder: The effect of sex on attributions of causality. Journal of Personality and Social Psychology; 30. $846-855$

Gjesme. T. (1981) Is there any future in achievement motivation? Motivation and Emotion, $5,115-138$

Heckhausen, H. (1980) Motivation und soziales Handeln. Berlin Heidelberg New York: Springer

Hübner-Funk. S., Lösch, H., Rathgeber, R., \& Schefold, W. (1982/83) Die Shell-Studie 18: ein Bild von Jugend. Zwei aktuelle Themen: Jugend und Zukunft. LiteraturRundschau der Neuen Praxis

Jugendwerk der Deutschen Shell (Ed.) (1982) Jugend '81. Lebensentwürfe - Alltagskulturen - Zukunftsbilder. Opladen: Leske \& Budrich

Klineberg. St. L. (1967) Changes in outlook on the future between childhood and adolescence. Journal of Personality and Social Psychology, 7, 185- 193

Lamm. H., Schmidt. R. W.. \& Trommsdorff, G. (1976) Sex and social class as determinants of future orientation (time perspective) in adolescents. Journal of Personality and Social Psychology, 34, 317-326

Landau, S. F. (1975) Future time perspective of delinquents and non-delinquents: The effect of institutionalization. Criminal Justice and Behavior, 2, 22-36

Landau, S. F. (1976) Delinquency, institutionalization, and time orientation. Journal of Consulting and Clinical Psychology, 44, 745-759

LeShan, L. L. (1952) Time orientation and social class. Journal of Abnormal and Social Psychology, 47, 589-592

LeVine, J. \& Wang, M. (1983) Teacher and student perceptions: Implications for learning. Hillsdale, N. J.: Erlbaum

Lewin, K. (1948) Time perspective and morale. In: K. Lewin (Ed.), Resolving social conflicts (pp. 103-124). New York: Harper

Lewin. K. (1965) Group decision and social change. In: H. Proshansky \& B. Seidenberg (Eds.). Basic studies in social psychology (pp. 423-437). London: Holt/Rinehart/ Winston

Mischel, W. (1974) Processes in delay of gratification. In: L. Berkowitz (Ed.), Advances in experimental social psycholog. v. Vol. 7. New York: Academic Press

Piaget. J. (1946) Le développement de la notion de temps chez l'enfant. Paris: P. U. F

Piaget. J. (1966) Time perception in children. In: J. P. Frazer (Ed.), The voices of time (pp. 202-216). New York: G. Braziller

Rosenthal. R. \& Jacobson, L. (1968) Pygmalion in the classroom. New York: Holt, Rinehart \& Winston

Rotter. J. B. (1966) Generalized expectancies for internal versus external control of reinforcement. Psychological Monograph, 80 (No. 609)

Shannon. L. (1975) Development of time perspective in three cultural groups: A cultural difference or an expectancy interpretation. Developmental Psychology, 11, 114-115

Shannon. L. (1976) Age change in time perception in native Americans, Mexican Americans. and Anglo Americans. Journal of Cross-Cultural Psychology, 7, 117 
Stapf. L. H.. Herrmann. Th.. Stapf. A.. \& Stäcker. K. (1972) Psychologie des elterlichen Erzie'lungsstils. Bern/Stuttgart: Huber

Stein. K. B.. Sarbin. T. R.. \& Kulik. J. A. (1968) Future time perspectives: Its relation to the socialization process and the delinquent role. Journal of Consulting and Clinical Psichology: 32, 257-264

Trommsdorff, G. (1983) Future orientation and socialization. International Journal of Psichologi; 18, 381-406

Trommsdorff. G., Burger, C., Füchsle. T., \& Lamm. H. (1978 a) Erziehung für die Zukunft. Düsseldorf: Schwann

Trommsdorff, G.. Burger, C.. \& Füchsle, T. (1980) Geschlechtsdifferenzen in der Zukunftsorientierung. Zeitschrift für Soziologie, 9, 366-377

Trommsdorff. G., Burger, C.. \& Füchsle, T. (1982) Social and psychological aspects of future orientation. In: M. Irle (Ed.), Sociopsychological aspects of decision-making (chapter 6). Berlin: De Gruyter

Trommsdorff, G.. Haag, C.. \& List, R. (1979) Zukunftsorientierung, Belohnungsaufschub und Risikobereitschaft bei weiblichen jugendlichen Delinquenten. Kölner Zeitschrifi für Soziologie und Sozialpsychologie, 3, 732- 745

Trommsdorff, G. \& Lamm. H. (1975) An analysis of future orientation and some of its social determinants. In: J. T. Fraser \& N. Lawrence (Eds.). The study of time (pp. 342-361). Berlin Heidelberg New York: Springer

Trommsdorff, G. \& Lamm, H. (1980) Future orientation of institutionalized delinquents and nondelinquents. European Journal of Social Psychology, 10, 247-278

Trommsdorff, G., Lamm, H., \& Schmidt, R.-W. (1978b) A longitudinal study of adolescents' future orientation (time perspective). Journal of Youth and Adolescence, 8, $131-147$

Vroom, V. H. (1964) Work and motivation. New York: Wiley

Wilpert. C. (1980) Die Zukunft der zweiten Generation - Erwartungen und Verhaltensmöglichkeiten ausländischer Kinder. Frankfurt a. M.: Campus. 